\title{
On the umbrella model for supported vanadium oxide catalysts
}

\author{
Joost N.J. van Lingen ${ }^{\mathrm{a}, \mathrm{b}, *}$, Onno L.J. Gijzeman ${ }^{\mathrm{a}}$, Bert M. Weckhuysen ${ }^{\mathrm{a}}$, Joop H. van Lenthe ${ }^{\mathrm{b}}$ \\ a Department of Inorganic Chemistry and Catalysis, Debye Institute, Utrecht University, PO Box 80083, 3508 TB Utrecht, The Netherlands \\ ${ }^{\mathrm{b}}$ Theoretical Chemistry Group ${ }^{1}$, Debye Institute, Utrecht University, PO Box 80083, 3508 TB Utrecht, The Netherlands
}

Received 24 June 2005; revised 3 January 2006; accepted 5 January 2006

Available online 9 February 2006

\begin{abstract}
An earlier-proposed model for the molecular structure of $\mathrm{VO}_{4}$ species on alumina was tested and compared with the pyramid model on a silica support. The model can be described as a chemisorbed $\mathrm{O}_{\text {support }}-\mathrm{V}=\mathrm{O}\left(\mathrm{O}_{2}\right)$ species with a similar geometry as on alumina. Results of DFT calculations on this model are consistent with the experimental Raman and EXAFS data collected on low-loaded silica-supported vanadium oxide catalysts. The band observed at $915 \mathrm{~cm}^{-1}$ is assigned to an $\mathrm{O}-\mathrm{O}$ stretch vibration. The thermal motion of the bound $\mathrm{O}_{2}$ molecule can explain the broadness of this band. These findings, in combination with our previous work, demonstrate that the umbrella model is a viable, internally consistent model for supported vanadium oxide catalysts at least at low loadings.

(c) 2006 Elsevier Inc. All rights reserved.
\end{abstract}

Keywords: Vanadium oxide; Silica; Molecular structure; DFT calculations; EXAFS and Raman spectroscopy

\section{Introduction}

Supported vanadium oxide catalysts represent an important class of heterogeneous catalysts that are widely used in the chemical industry in various selective oxidation reactions, as well as for the selective reduction of $\mathrm{NO}_{x}$ emissions [2-5]. These catalysts consist of an active vanadium oxide phase deposited on the surface of a high-surface area oxide support, such as $\mathrm{SiO}_{2}, \mathrm{Al}_{2} \mathrm{O}_{3}, \mathrm{TiO}_{2}$, and $\mathrm{ZrO}_{2}$. The molecular structure of these supported vanadium oxide species has been studied by a wide variety of spectroscopic techniques, including Raman, ${ }^{51} \mathrm{~V}$ NMR, UV-vis-NIR, EXAFS, XANES, ESR, and XPS [6-19]. The reaction rate and selectivity strongly depend on the metal oxide loading, the support oxide material, and the degree of hydration. Several review papers have described the current understanding of these catalyst systems [6,20-22].

The most common opinion is that the $\mathrm{VO}_{4}$ monomeric species in dehydrated supported vanadium oxide catalysts can be envisaged as a pyramidal structure with one $\mathrm{V}=\mathrm{O}$ bond and three $\mathrm{V}-\mathrm{O}_{\text {support }}$ bonds (Figs. 1d-1f) [23-27]. This model

\footnotetext{
* Corresponding author.

E-mail address: j.n.j.vanlingen@ @hem.uu.nl (J.N.J. van Lingen).

1 Affiliated to Organic Chemistry and Catalysis.
}

is characterized by a vibration at $\sim 1030 \mathrm{~cm}^{-1}$ [28]. Through comparison with reference compounds, this band has been assigned to the $\mathrm{V}=\mathrm{O}$ stretch vibrational mode [28]. A second, rather broad Raman band has been observed at $\sim 915 \mathrm{~cm}^{-1}$ that increases in intensity with increasing vanadium oxide loading, leading to the assignment of this band to polymeric species, that is, either a $\mathrm{V}-\mathrm{O}-\mathrm{V}$ or an $\mathrm{O}-\mathrm{V}-\mathrm{O}$ vibration [17]. Thus, two Raman features-the 1030 and $915 \mathrm{~cm}^{-1}$ bands-have been clearly documented. Based on the foregoing interpretation, these features have been used as fingerprints to distinguish monomeric and polymeric surface $\mathrm{VO}_{4}$ units. ${ }^{18} \mathrm{O}$ labeling experiments, in conjunction with Raman spectroscopy [29], provide evidence for this assignment.

Recently, two groups have challenged the assignment of the second band at $915 \mathrm{~cm}^{-1}$ to a polymeric vibration. Magg et al. [30] ascribed the IR band observed at approximately $915 \mathrm{~cm}^{-1}$ for their $\mathrm{VO}_{x} / \mathrm{Al}_{2} \mathrm{O}_{3}$ catalysts to the $\mathrm{Al}-\mathrm{O}-\mathrm{V}$ stretch vibration. They cannot make that claim when vanadium oxide is supported by silica, however. We recently proposed [1] an alternative model, called the "umbrella" model (Figs. 1a-1c), in which the $\mathrm{VO}_{4}$ unit, now containing one $\mathrm{V}=\mathrm{O}$ unit and an active oxygen "molecule" bound to the vanadium atom, is linked to the surface via only one $\mathrm{V}-\mathrm{O}$ support bond. This proposal was based on DFT calculations and temperature-dependent Raman 

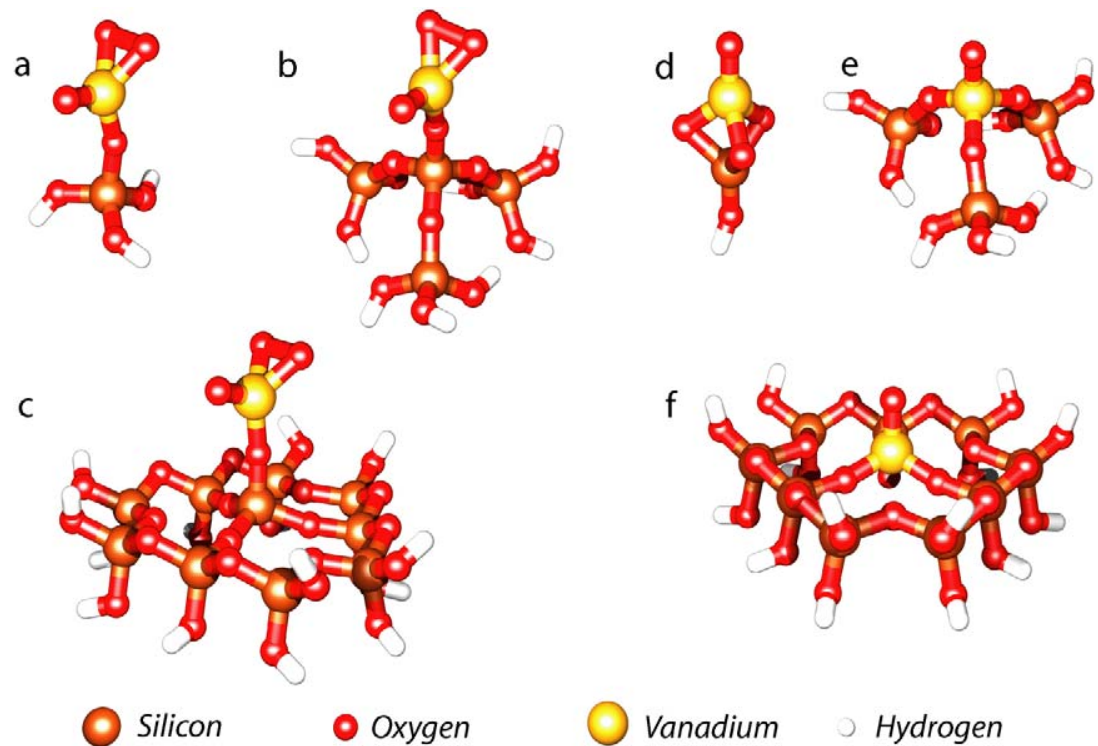

Vanadium Hydrogen

Fig. 1. The molecular structure of six cluster models (umbrella a-c and pyramid d-f) for a supported vanadium oxide $\left(\mathrm{VO}_{4}\right)$ catalyst used for DFT calculations in this paper.

spectroscopy data on $\mathrm{Al}_{2} \mathrm{O}_{3}$-supported vanadium oxide catalysts, which could not be explained with the pyramidal model. In our current view, the "polymeric" band at $915 \mathrm{~cm}^{-1}$ corresponds to an $\mathrm{O}-\mathrm{O}$ stretching vibration, whereas the peak at $1030 \mathrm{~cm}^{-1}$ still is assigned to a $\mathrm{V}=\mathrm{O}$ stretch vibration.

In another paper from our group on a $\mathrm{VO}_{x} / \mathrm{Al}_{2} \mathrm{O}_{3}$ catalyst [31], it was shown with EXAFS that on a low-loaded vanadium oxide catalyst, the $\mathrm{V}$ atom is surrounded by four oxygen atoms, three of these present at a distance of $1.72 \AA$ and one present at a much shorter distance of $1.58 \AA$, thus providing support to the "umbrella" or "pyramidal" structure. But this article [31] demonstrated that the V-O-V bonds did not exist, whereas the $915 \mathrm{~cm}^{-1}$ Raman band was observed for this catalyst. Thus the exclusive assignment of this band to a polymeric species does not seem valid.

In the current study, we expand our discussion of the umbrella model [1] to the silica support. Previously, it was shown that the $\mathrm{VO}_{4}$ species is only monomeric on this support [17,28]. A series of well-defined $\mathrm{VO}_{x} / \mathrm{SiO}_{2}$ materials with increasing vanadium oxide loading was prepared and analyzed with EXAFS and Raman spectroscopy, and the data were compared with those from DFT calculations. To sum up, we evaluate the umbrella and pyramid models by giving an overview of the experimental data that the models are able to explain and commenting on the implications for the reactivity of supported vanadia oxide catalysts.

\section{Experimental}

\subsection{Catalyst preparation}

A series of well-defined supported vanadium oxide catalysts with increasing vanadium oxide loadings were prepared using $\mathrm{SiO}_{2}$ (homemade; pore volume, $0.70 \mathrm{ml} \mathrm{g}^{-1}$; surface area, $600 \mathrm{~m}^{2} \mathrm{~g}^{-1}$ ) as the support oxide. The $\mathrm{SiO}_{2}$ support was prepared by the sol-gel method according to a slightly altered
Table 1

Overview of the supported vanadium oxide catalysts under investigation, together with their corresponding sample code, vanadium oxide loading, surface density and surface monolayer coverage

\begin{tabular}{lrlc}
\hline Sample & $\mathrm{wt} \% \mathrm{~V}$ & $\mathrm{VO}_{x} / \mathrm{nm}^{-2}$ & $\begin{array}{c}\text { \% of monolayer } \\
\text { coverage reached }\end{array}$ \\
\hline $1 \mathrm{~V}-\mathrm{Si}$ & 1.05 & 0.118 & 5.1 \\
$2 \mathrm{~V}-\mathrm{Si}$ & 2.08 & 0.236 & 10.3 \\
$4 \mathrm{~V}-\mathrm{Si}$ & 4.05 & 0.470 & 20.4 \\
$8 \mathrm{~V}-\mathrm{Si}$ & 8.33 & 1.011 & 43.9 \\
$12 \mathrm{~V}-\mathrm{Si}$ & 12.90 & 1.648 & 71.6 \\
$16 \mathrm{~V}-\mathrm{Si}$ & 16.40 & 2.183 & 94.9 \\
\hline
\end{tabular}

recipe [32], using $\mathrm{HNO}_{3}$ instead of $\mathrm{HCl}$. The catalysts were prepared with the incipient wetness impregnation technique using a $\mathrm{NH}_{4} \mathrm{VO}_{3}$ (Merck, p.a.) solution with oxalic acid (Brocacef, $99.25 \%$ pure). The catalysts were dried at room temperature for $16 \mathrm{~h}$ at $393 \mathrm{~K}$, then calcined at $773 \mathrm{~K}$ for $3 \mathrm{~h}$. Table 1 lists all of the catalysts under investigation together with the catalyst code used throughout the paper. The amount of $\mathrm{VO}_{x} \mathrm{~nm}^{-2}$ on the catalysts is compared with the theoretical monolayer for monomers as described by Khodakov et al. [33].

\subsection{Spectroscopic characterization}

Raman measurements were carried out on dehydrated catalyst samples in a special cell with a quartz window. Details on this equipment can be found elsewhere [34]. Dehydration was performed in a stream of $\mathrm{O}_{2}\left(40 \mathrm{ml} \mathrm{min}^{-1}\right)$ at $723 \mathrm{~K}$ for $3 \mathrm{~h}$. Raman spectra (exposure time of $50 \mathrm{~s}, 50$ accumulations) were collected at room temperature with a Kaiser RXN spectrometer equipped with a 532-nm diode laser. A 5.5" noncontact objective was used for beam focusing and collection of scattered radiation. EXAFS experiments at beamline E4 in Hasylab (Hamburg, Germany) and data analysis were carried out as described previously [31]. 


\subsection{DFT calculations}

Quantum chemical calculations were done with the GAMESS-UK program [35]. Exchange correlation energy was added to the calculations using the B3LYP density functional $[36,37]$. All calculations were performed with the LanL2DZ basis set and accompanying ECPs from the EMSL basis set database. The structures of the clusters were optimised to a maximum gradient of $4.4 \times 10^{-5}$. After optimizing, harmonic vibrational frequencies were calculated. As is well known, the calculated frequencies for DFT wavefunctions are slightly too high compared with experiments [38]. A scaling factor of 0.95 is commonly used to correct for this deficiency $[39,40]$. This factor has been incorporated in all data.

Several cluster models were investigated. Fig. 1a shows the umbrella model presented in a previous paper [1]. The support of this model consists of one oxygen atom, one silicon atom, and three $\mathrm{OH}$-groups only. Larger clusters were considered, as shown in Figs. 1b and 1c. In the largest cluster, the support is modeled by $\mathrm{O}-\mathrm{Si}_{10} \mathrm{O}_{27} \mathrm{H}_{15}$, which represents a small part of the amorphous silica support structure. For comparison, pyramid model clusters (Figs. 1d, 1e, and 1f) were designed with the same support sizes used for the umbrella models.

In the vibrational analysis, the atoms of the support are assigned a large weight (2000 amu) to simulate a truly rigid lattice. This removes all vibrations originating from the support and all couplings between the support and the $\mathrm{VO}_{4}$ species, including a possible V-O-Si vibration. Thus, referring to Fig. 1a, in the case of the smallest umbrella model, we assign a huge mass to the $\mathrm{Si}$ and $\mathrm{OH}$ groups underneath the $\mathrm{O}-\mathrm{VO}_{3}$. This method has been applied to all cluster sizes. In two cases (Figs. $1 \mathrm{~b}$ and 1e), the vibrational frequencies were calculated with the correct weights assigned to the support to check the position of the vibrations calculated with the rigidly fixed support. Raman intensities associated with the vibrations were calculated in the following manner. Because GAMESS-UK does not support the calculation of Raman intensities with DFT, the intensities were calculated with HF on the HF-optimised clusters $b$ and $e$ in Fig. 1. In addition, the $\mathrm{H}$ atoms of the support were frozen to prevent them from having a large influence on the calculated intensities. The vibrations were then linked with the resulting vibrations from the DFT HESSIAN by comparing their movement. The infrared intensities were virtually identical in both cases. Both HF and DFT intensities were calculated using the TZVP basis set [41].

To get an impression of the influence of structural deformation on the vibrational frequencies, three possible structural changes from the optimal geometry were simulated on the small and medium umbrella models (Figs. $1 \mathrm{~b}$ and 1c). In all of these changes, the geometry was optimised with only the varied parameter fixed, after which the vibrational modes were calculated. First, the $\mathrm{VO}_{3}$ species of the umbrella model was rotated with respect to the support over $60^{\circ}$. Taking into account the symmetry of the support, this rotation covers all positions. Second, the $\mathrm{Si}-\mathrm{O}-\mathrm{V}$ bond angle was altered from $120^{\circ}$ to $240^{\circ}$. Finally, the distance between the centre of gravity of the bound $\mathrm{O}_{2}$ molecule and the $\mathrm{V}$ atom was changed from 1.5 to $1.8 \AA$.
The relative stability of the umbrella and pyramid models were difficult to assess, because direct comparison is not possible. We have tried to estimate it by calculating the reaction energy of the following reactions:

$$
\begin{aligned}
& \mathrm{H}_{3} \mathrm{VO}_{4}+\mathrm{Si}(\mathrm{OH})_{4}+(1 / 2) \mathrm{O}_{2} \\
& \quad \rightarrow \mathrm{OV}-\mathrm{O}_{3}-\mathrm{SiOH}+3 \mathrm{H}_{2} \mathrm{O}+(1 / 2) \mathrm{O}_{2}
\end{aligned}
$$

and

$$
\begin{aligned}
& \mathrm{H}_{3} \mathrm{VO}_{4}+\mathrm{Si}(\mathrm{OH})_{4}+(1 / 2) \mathrm{O}_{2} \\
& \quad \rightarrow \mathrm{O}_{3} \mathrm{~V}-\mathrm{O}-\mathrm{Si}(\mathrm{OH})_{3}+2 \mathrm{H}_{2} \mathrm{O}
\end{aligned}
$$

These reactions start with the same reactants and model the attachment of the vanadium oxide species to the surface. The first reaction yields a pyramid model; the second reaction, the umbrella structure. Calculations on this reaction were performed with the TZVP basis set to get more accurate results.

\section{Results}

\subsection{Spectroscopic results}

Raman experiments on the $\mathrm{VO}_{4} / \mathrm{SiO}_{2}$ catalysts after dehydration gave the spectra shown in Fig. 2. The blank spectrum, taken on only silica, shows three peaks in the $800-1200 \mathrm{~cm}^{-1}$ region, situated at 800,980 , and $1060 \mathrm{~cm}^{-1}$. These peaks can be assigned to vibrations in the silica lattice. From the spectra with $\mathrm{VO}_{4}$ present, it can be seen that in the region of 850 $1100 \mathrm{~cm}^{-1}$, three peaks are visible in the spectra at different loadings. The first extra peak appears immediately at the $1 \%$ loading on top of the silica band at $1060 \mathrm{~cm}^{-1}$ and becomes more intense with increasing loading. This sharp peak can be assigned to the well-documented $\mathrm{V}=\mathrm{O}$ stretch vibration at $1040 \mathrm{~cm}^{-1}$ [27]. A second sharp peak appears at loading of $12 \%$ and higher. This peak at $996 \mathrm{~cm}^{-1}$ is commonly assigned to the formation of crystalline $\mathrm{V}_{2} \mathrm{O}_{5}$ on the surface [42]. Finally, a broad band is seen at around $915 \mathrm{~cm}^{-1}$ at $2 \%$ loading and even perhaps at $1 \%$ loading. At least the blank sample shows a flat spectrum in that region, whereas the $1 \%$ catalyst shows similar trends as the higher-loaded samples. We have previously assigned this band to the $\mathrm{O}-\mathrm{O}$ stretch vibration of the peroxo group in the umbrella model [1]. Apart from these three peaks, the intensity of the broad band at $980 \mathrm{~cm}^{-1}$ increases with increasing $\mathrm{VO}_{4}$ loading.

EXAFS studies on the 1V-Si sample yielded the following structural parameters from the R-space fit: The first shell consists of $1 \mathrm{O}$ atom at $1.58 \AA$ from the central $\mathrm{V}$ atom, and fitting of the second shell gave $3.07 \mathrm{O}$ atoms at a distance of $1.77 \AA$. These results are included in Table 2.

\subsection{DFT calculations}

Optimization calculations on the umbrella clusters depicted in Fig. 1 resulted in three structures. The most important distances are shown in Table 2. Also included in this table are the calculated vibrational frequencies at $800-1100 \mathrm{~cm}^{-1}$, along with the calculated distances and frequencies for the pyramid clusters (shown in Figs. 1d and 1e). Calculating the Hessian 


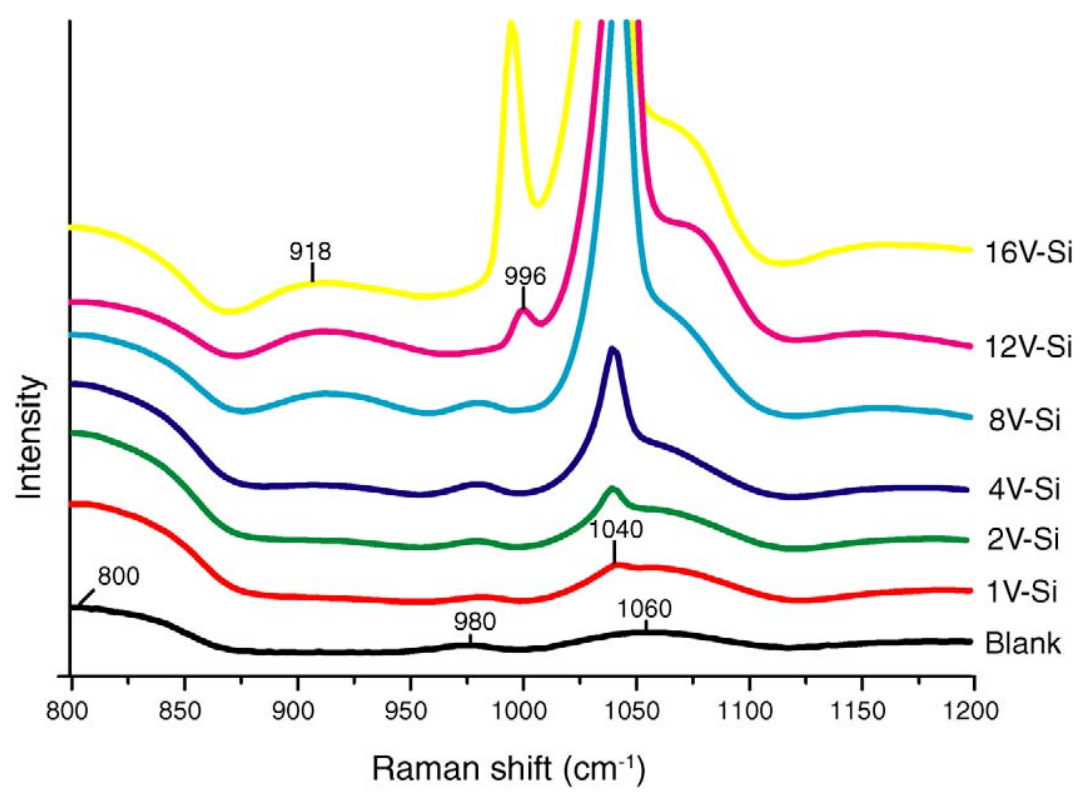

Fig. 2. Raman spectra of samples (a) 1V-Si; (b) 2V-Si; (c) 4V-Si; (d) 8V-Si; (e) 12V-Si and (f) 16V-Si measured under dehydrated conditions at room temperature. The spectra have been normalised and positioned above each other. For clarity the $y$-axis is cut at 3000 units and the labels of the spectra have been put to the right of them. Important peak positions have been indicated in the figure.

Table 2

Computed data wit the LanL2DZ ecp basis set for the four umbrella structures combined with the EXAFS and Raman results considered in this work. $\mathrm{O}_{\mathrm{s}}$ is the support $\mathrm{O}$ atom. All distances are in $\AA$; vibrational modes are in $\mathrm{cm}^{-1}$. In brackets the coordination number for the atoms at this distance resulting from the EXAFS experiments or the DFT calculations is given

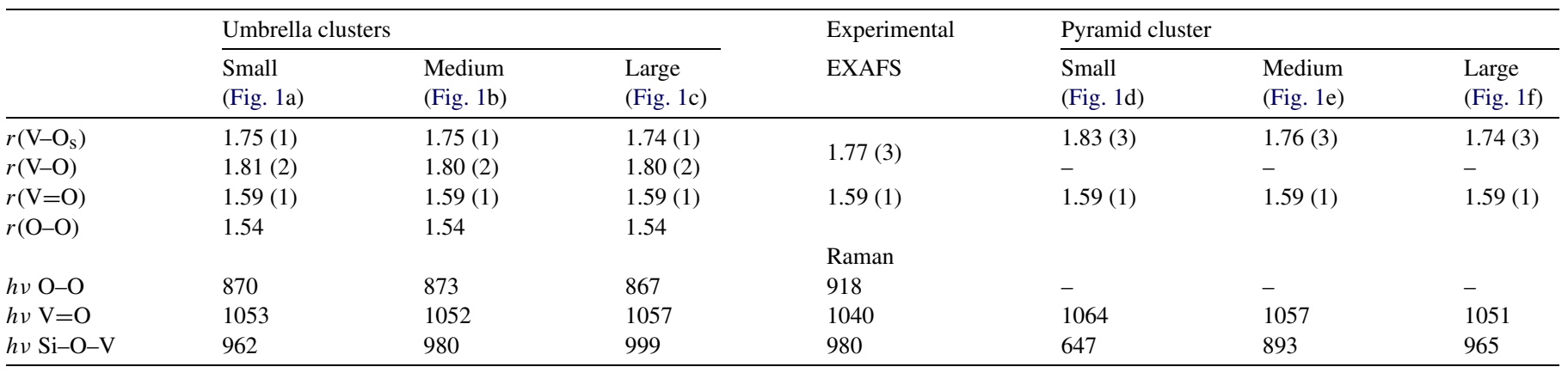

with the support atoms at their normal weights (i.e., assuming a nonrigid lattice for Figs. $1 \mathrm{~b}$ and 1e) gives a maximum shift in frequency of $2 \mathrm{~cm}^{-1}$.

Distorting the optimal structure of the umbrella model resulted in the graphs shown in Figs. 3 and 4. These graphs plot the total energies and frequencies belonging to the vibrations assigned to the 915 and $1040 \mathrm{~cm}^{-1}$ bands against the structural changes. To allow a clearer comparison between these three distortions, the scales of the graphs have been kept the same. A horizontal line is inserted at the 0.001 hartree level, which is about $1 \mathrm{kT}$ at room temperature. The results for the rotation on the surface of the $\mathrm{VO}_{4}$ are not shown here, because this distortion had almost no effect on the energy and frequencies of the clusters. Calculations regarding the stability of the pyramid and the umbrella model resulted in reaction energies of $262 \mathrm{~kJ} \mathrm{~mol}^{-1}$ for the formation of the umbrella species (reaction (2)) and $567 \mathrm{~kJ} \mathrm{~mol}^{-1}$ for the creation of the pyramid species (reaction (1)).

\section{Discussion}

\subsection{EXAFS and DFT studies}

The change of the support from alumina in our previous work $[1,31]$ to silica does not really change the optimized structures for the models, as shown in Figs. 1a-1f. The umbrella model has one $\mathrm{O}$ atom placed at $1.58 \AA$, another $\mathrm{O}$ atom at $1.75 \AA$, and two $\mathrm{O}$ atoms at $1.80 \AA$, which is comparable to the structure on the alumina support. Also it can be concluded from Table 2 that these distances do not change significantly when the tiny support (Fig. 1a) is replaced with one of the larger ones (Figs. $1 \mathrm{~b}$ and $1 \mathrm{c}$ ). The size of the silica support is immaterial in the umbrella model.

The pyramid models on almost the same supports as the umbrella models show that the $\mathrm{O}_{\text {support }}-\mathrm{V}$ distance decreases when using a larger support for this model. This is probably due to the fact that in the smaller clusters, the $\mathrm{V}-\mathrm{O}-\mathrm{Si}$ angles are more strained. They can release this strain by increasing the 


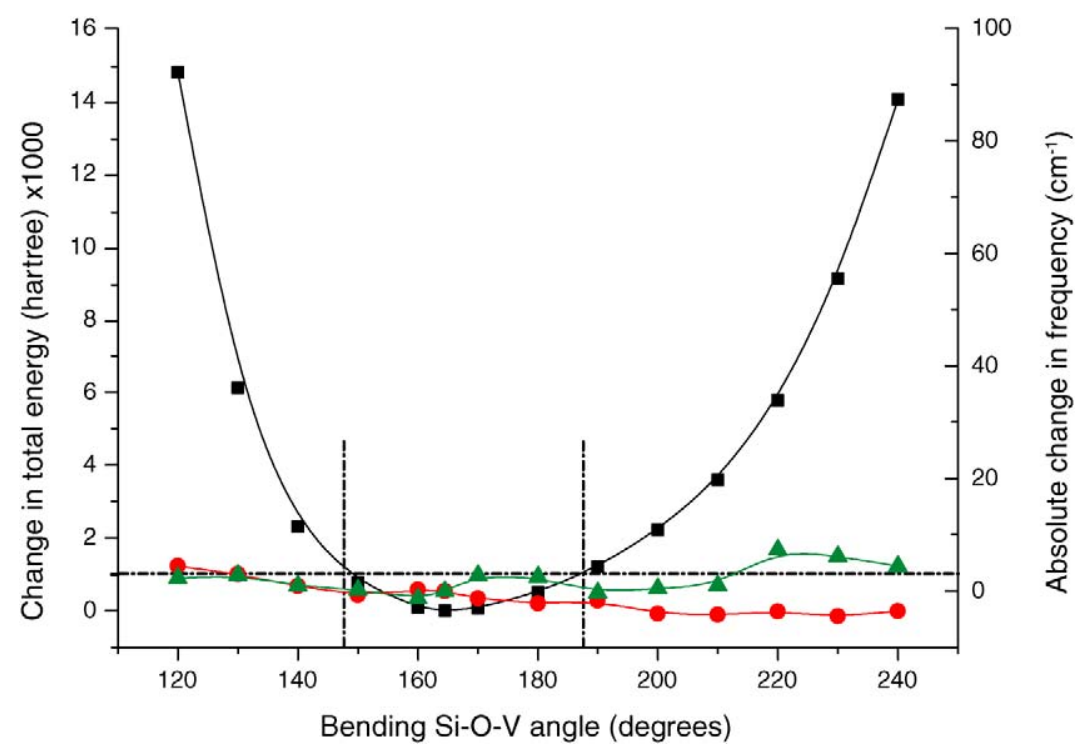

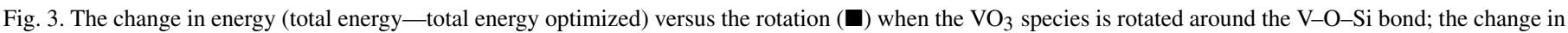
frequency (frequency_optimized frequency) for the $915(\mathbf{O})$ and $1040 \mathrm{~cm}^{-1}(\mathbf{\Delta})$ Raman bands, when the angle of the V-O-Si bond is varied.

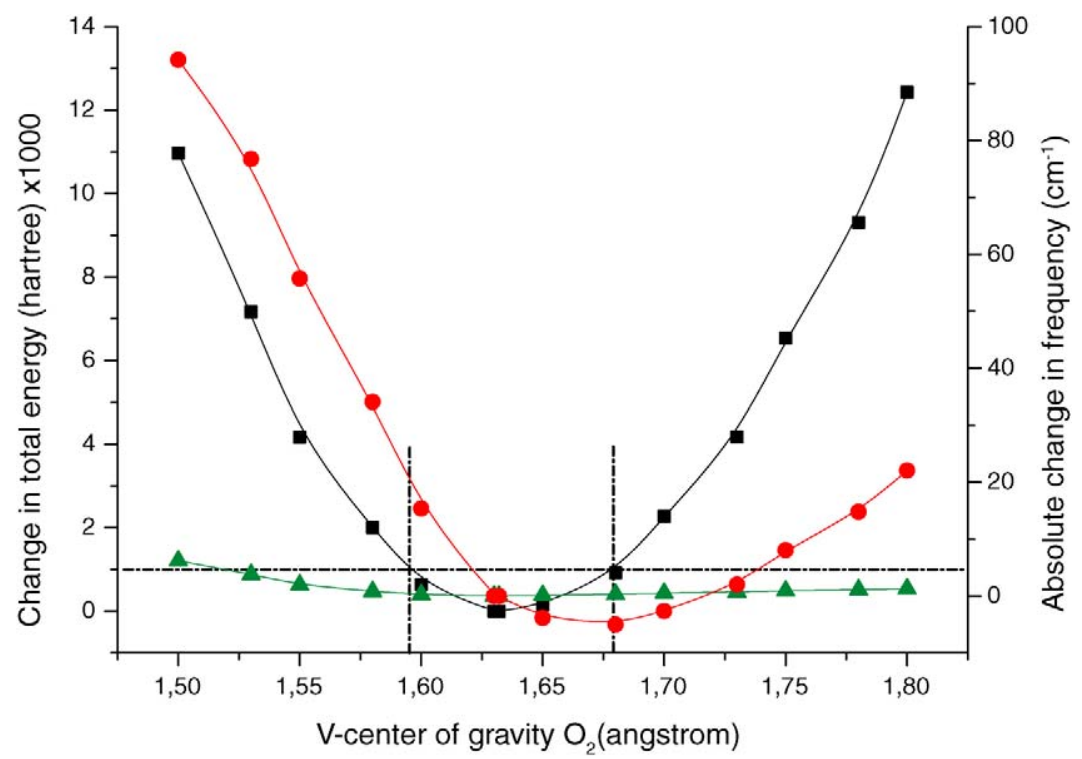

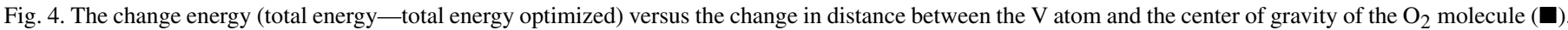

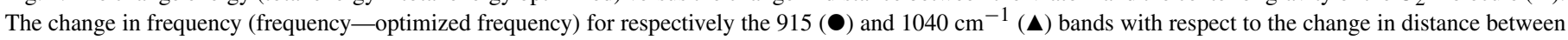
the $\mathrm{V}$ atom and the $\mathrm{O}_{2}$ molecule.

distances, which will probably cost less energy than straining the angles.

The EXAFS fit results in one $\mathrm{O}$ atom at $1.58 \AA$ and three $\mathrm{O}$ atoms at 1.77 from the central $\mathrm{V}$ atom. This compares very well to the internal distances of the umbrella model (Table 1) if we take into account that EXAFS cannot distinguish between 1.75 and $1.8 \AA$ and sees this as three $\mathrm{O}$ atoms at an average of $1.77 \AA$. The same applies for the pyramid models.

\subsection{Raman experiments and DFT studies: peak positions and intensities}

Raman experiments (Fig. 2) demonstrate one clear sharp peak at $1040 \mathrm{~cm}^{-1}$ and a weak, very broad band at ca.
$915 \mathrm{~cm}^{-1}$. Next to this, the peak at $980 \mathrm{~cm}^{-1}$ shows an increased intensity with increasing loading. The same features were recently observed by Nguyen et al. [43].

DFT Hessian calculations with a LanL2DZ basis set for the umbrella model [1] clearly show that an $\mathrm{O}-\mathrm{O}$ stretching vibration of the bound $\mathrm{O}_{2}$ molecule has a frequency after scaling at $870 \mathrm{~cm}^{-1}$ (Table 2). This is reasonably close to $915 \mathrm{~cm}^{-1}$. In more time-consuming calculations, however, with a TZVP basis set using the same scaling factor, the $\mathrm{O}-\mathrm{O}$ stretching vibration shifts upward by approximately $30 \mathrm{~cm}^{-1}$ to a position at ca. $903 \mathrm{~cm}^{-1}$ (Table 3). Tables 2 and 3 also show a Si-O-V vibration at ca. $980 \mathrm{~cm}^{-1}$. This vibration has a lower intensity in Raman then the other two vibrations but is still sufficiently high to be measurable. Its presence explains the increase of intensity 
Table 3

Computed relative intensities in infrared and Raman for the most intense vibrational frequencies involving vanadium calculated with the TZVP basis set

\begin{tabular}{lccc}
\hline Vibration & $\begin{array}{l}\text { Frequency } \\
\left(\mathrm{cm}^{-1}\right)\end{array}$ & $\begin{array}{l}\text { Intensity } \\
\text { infrared } \\
\left(\mathrm{km} \mathrm{mol}^{-1}\right)\end{array}$ & $\begin{array}{l}\text { Intensity } \\
\text { Raman } \\
(\text { a.u. })\end{array}$ \\
\hline Pyramid & & & \\
$\mathrm{V}=\mathrm{O}$ & 1036 & 159 & 2.2 \\
Antisymm O $\mathrm{O}_{3}-\mathrm{V}=\mathrm{O}$ & 1024 & 903 & 6.3 \\
Symm $\mathrm{O}_{3}-\mathrm{V}=\mathrm{O}$ & 1046 & 72 & 23.6 \\
$\mathrm{Si}-\mathrm{O}-\mathrm{V}$ & 906 & 1789 & 15.8 \\
& & & \\
Umbrella & 1038 & 116 & 14.2 \\
$\mathrm{~V}=\mathrm{O}$ & 978 & 1823 & 6.9 \\
$\mathrm{Si}-\mathrm{O}-\mathrm{V}$ & 903 & 324 & 31.7 \\
$\mathrm{O}-\mathrm{O}$ & & & \\
\hline
\end{tabular}

of the experimental band at $980 \mathrm{~cm}^{-1}$. The intensity of the $\mathrm{Si}-$ $\mathrm{O}-\mathrm{V}$ vibration in infrared is just the opposite of that in Raman, with the $980 \mathrm{~cm}^{-1}$ band being the most prominent. Thus, this should be the major peak observed experimentally. An example of this is the work of Scott et al. [44-46], in which an IR band at $959 \mathrm{~cm}^{-1}$ was observed and assigned to a $\mathrm{Si}-\mathrm{O}-\mathrm{V}$ vibration, in agreement with our calculations. Possibly the appearance of a peak at $1005 \mathrm{~cm}^{-1}$ in the IR spectrum of Magg et al. [30] can be explained by the intense $\mathrm{Si}-\mathrm{O}-\mathrm{V}$ vibration calculated here. Together with the $\mathrm{V}=\mathrm{O}$ stretching vibration, this gives the three bands at 915,980 and $1040 \mathrm{~cm}^{-1}$, which are seen in the experimental Raman spectra at low loadings (Fig. 2).

The calculations done on the pyramid models can explain the presence of the $\mathrm{V}=\mathrm{O}$ vibration at $1036 \mathrm{~cm}^{-1}$ in the Raman spectra. A band proposed by Magg et al. [30] to be a V-O-Al mode in the same $900-1000 \mathrm{~cm}^{-1}$ region for the pyramid model supported by alumina is calculated at around $906 \mathrm{~cm}^{-1}$ for a silica support pyramid, as seen in Table 3 . This vibration is an asymmetric $\mathrm{VO}_{3}$ vibration rather than a $\mathrm{Si}-\mathrm{O}-\mathrm{V}$ vibration. Table 2 shows that the position of this peak actually depends on the size of the cluster, ranging from 647 to $965 \mathrm{~cm}^{-1}$. This makes the exact position of this peak doubtful. However, this peak has the greatest infrared intensity, as shown in Table 3. It is missing in the experimental IR spectra from Scott et al. [39, 45,46] and Magg et al. [30], however.

In summary, the umbrella models are able to give a theoretical interpretation for the bands at 915, 980, and $1040 \mathrm{~cm}^{-1}$ experimentally observed for silica supported vanadium oxide catalysts by either Raman or IR. The pyramid models are able to explain the band at $1040 \mathrm{~cm}^{-1}$ as a $\mathrm{V}=\mathrm{O}$ vibration and might explain the existence of the 920 band as an asymmetric $\mathrm{VO}_{3}$ vibration, but fails to give an interpretation for the peak at $980 \mathrm{~cm}^{-1}$.

\subsection{Raman experiments and DFT studies: band widths}

The broadness of the peak at $915 \mathrm{~cm}^{-1}$ cannot be explained by the first two obvious possibilities, rotation on the surface of the $\mathrm{VO}_{3}$ umbrella and altering of the $\mathrm{Si}-\mathrm{O}-\mathrm{V}$ bond angle (Fig. 3). These have almost no influence on the frequencies of the $\mathrm{V}=\mathrm{O}$ and $\mathrm{O}-\mathrm{O}$ bands. The third possibility, however, shows that the distance from the $\mathrm{O}_{2}$ molecule to the $\mathrm{V}$ atom can range from 1.59 to $1.68 \AA$ without increasing the energy of the system by more than $1 \mathrm{kT}$. This does not affect the frequency of the $\mathrm{V}=\mathrm{O}$ band, but changes the $\mathrm{O}-\mathrm{O}$ frequency by $27 \mathrm{~cm}^{-1}$. Thus the change in the position of the bound $\mathrm{O}_{2}$ molecule caused by thermal energy does indeed lead to a sharp $\mathrm{V}=\mathrm{O}$ band and a broad $\mathrm{O}-\mathrm{O}$ band.

\subsection{DFT studies: stability}

Concerning the stability of the umbrella model, the following conclusions can be drawn. When we consider the reaction energies of the two reaction equations, the formation of the umbrella model $\left(262 \mathrm{~kJ} \mathrm{~mol}^{-1}\right)$ costs half the energy of the formation of the pyramid model $\left(567 \mathrm{~kJ} \mathrm{~mol}^{-1}\right)$. This difference is due in part to the strains on angles and distances needed to form the pyramid model. In the small pyramid molecule formed in the reaction, this will be less than in a real surface. The surrounding atoms on the real surface will be less able to compensate for the strains, and thus it will even cost more energy to put it on a surface. Next to this energy difference, is the fact that $\mathrm{OH}$ groups are rather scarce on the surface. Zhuravlev [47] states that at $300{ }^{\circ} \mathrm{C}$ the average area occupied by one $\mathrm{OH}$ group on the surface of amorphous silica equals $0.42 \mathrm{~nm}^{2}$. This makes it very hard to find a surface spot with three $\mathrm{OH}$ groups close enough to form a pyramid active site. The umbrella model only needs one $\mathrm{OH}$ group and can be created everywhere once a hydroxyl group is present on the surface.

The peroxo group is rather tightly bound to the $\mathrm{O}=\mathrm{V}-\mathrm{O}_{\mathrm{s}}$ $\left(-352.3 \mathrm{~kJ} \mathrm{~mol}^{-1}\right.$ from DFT calculations). High temperatures are needed to remove the bounded $\mathrm{O}_{2}$ molecule. The oxygen atoms in the $\mathrm{O}_{2}$ molecule are very reactive and will react with impurities or reactants in the catalytic reaction. The presence of an umbrella model with the peroxo group replaced by two $\mathrm{OH}$ groups cannot be excluded. This will replace the $\mathrm{O}-\mathrm{O}$ vibration at $920 \mathrm{~cm}^{-1}$ by two vibrations at around $800 \mathrm{~cm}^{-1}$ related to the symmetric and antisymmetric bending of the $\mathrm{OH}$ groups. Therefore, the species may be present, but it cannot be the only V-containing unit on the surface, as the $920 \mathrm{~cm}^{-1}$ band is observed experimentally.

\subsection{Considering the umbrella model}

Considering the umbrella model and combining all of the results from this paper and our previous work [1,31], we can summarize our conclusions as follows:

- The umbrella model complies with our EXAFS studies on $\mathrm{VO}_{4}$ species supported on either silica or alumina.

- Calculations on the umbrella clusters give three vibrations; the $\mathrm{V}=\mathrm{O}$ stretch at $1050 \mathrm{~cm}^{-1}$, an $\mathrm{Si}-\mathrm{O}-\mathrm{V}$ mode at $980 \mathrm{~cm}^{-1}$ and the $\mathrm{O}-\mathrm{O}$ stretch in the peroxo group at $870 \mathrm{~cm}^{-1}\left(900 \mathrm{~cm}^{-1}\right.$ with the TZVP basis set), which can be found in our experimental Raman spectra.

- The shift of the 1040 and $920 \mathrm{~cm}^{-1}$ peaks by isotope labelling of the $\mathrm{O}$ atoms conducted by Weckhuysen et al. [29] can be reproduced by DFT calculations [1]. 
- The $\mathrm{V}=\mathrm{O}$ stretch vibration peak is very sharp in the experimental spectra, whereas the band at $915 \mathrm{~cm}^{-1}$ is very broad. This broadness can be explained by the thermal motion of the bound $\mathrm{O}_{2}$, as was shown earlier.

- In a previous paper [1], we showed that the umbrella model gives the same experimentally observed behaviour when the temperature dependence of the peak at $1040 \mathrm{~cm}^{-1}$ is simulated on the alumina support. In both the experimental Raman and theoretical calculated data, the peak position shifts to a lower frequency with increasing temperature. The same trend can be seen if we simulate temperature dependence on a cluster supported by silica.

- To form an umbrella structure on the silica surface, only one surface $\mathrm{OH}$ group is needed.

- For a similar reaction where a $\mathrm{VOCl}_{3}$ molecule reacts with a silica surface, Scott et al. [44-46] found by EXAFS, NMR, and several spectroscopic techniques that only one $\mathrm{HCl}$ is released per connected $\mathrm{VOCl}_{3}$ unit. This corroborates the umbrella model. They also found an IR peak at $959 \mathrm{~cm}^{-1}$, which they assigned to a V-O-Si vibration. Our umbrella model clusters give the same interpretation to this peak position.

- The umbrella model gives more possibilities for a catalytic reaction and makes the reaction scheme simpler. Two $\mathrm{O}$ atoms are readily available for the reaction and one for intermediate $\mathrm{H}$ storage. After all oxygen atoms have been used, the catalyst can be reactivated by introducing a new $\mathrm{O}_{2}$ molecule at the end of the reaction cycle instead.

- In terms of stability, it takes less energy to form the umbrella model on the surface than it does for the pyramid model. The peroxo group is tightly bound to the $\mathrm{O}=\mathrm{V}-\mathrm{O}_{\mathrm{s}}$ structure but highly reactive.

\section{Conclusion}

The results presented in this paper and previous papers $[1,31]$ show that the umbrella model is a more viable internally consistent model for supported vanadium oxide catalysts at low loadings compared with the pyramid model. The umbrella model can be described as a chemisorbed $\mathrm{V}=\mathrm{O}\left(\mathrm{O}_{2}\right)$ species. All three oxygen atoms point away from the support surface. Two equal V-O distances are found at $1.79-1.80 \AA$, and one shorter $\mathrm{V}=\mathrm{O}$ bond is seen at $1.59 \AA$. The equivalent oxygens are separated by only $1.44-1.46 \AA$. The observed vibrational frequencies in the range of $900-1100 \mathrm{~cm}^{-1}$ can be assigned to $\mathrm{V}=\mathrm{O}\left(1030 \mathrm{~cm}^{-1}\right), \mathrm{O}-\mathrm{O}\left(915 \mathrm{~cm}^{-1}\right)$, and $\mathrm{Si}-$ $\mathrm{O}-\mathrm{V}\left(980 \mathrm{~cm}^{-1}\right)$ without invoking the presence of polymeric species. Thermal movement of the bound oxygen molecule can explain the broadness of the band at $915 \mathrm{~cm}^{-1}$. The presence of other molecular structures (e.g., where the peroxo group is replaced by two $\mathrm{OH}$ groups) may not be excluded. Multiple species may very well be present on the surface.

\section{Acknowledgments}

The authors thank D.E. Keller for contributing the experimental data needed for this article and fruitful discussions.
The EXAFS work at HASYLAB was supported by IHP contract HPRI-CI-2001-00140 from the European Commission. J.N.J.v.L. and J.H.v.L. acknowledge partial financial support from NWO/NCF for the use of supercomputer time on TERAS, SARA, The Netherlands (project SGO32). The LanL2 basis set was obtained from the EMSL Gaussian Basis Set database. B.M.W. acknowledges financial support from NRSCC, $\mathrm{NWO} / \mathrm{CW}$-Van der Leeuw, NWO/CW-VICI, and a EU-COST D15 program.

\section{References}

[1] O.L.J. Gijzeman, J.N.J. van Lingen, J.H. van Lenthe, S.J. Tinnemans, D.E Keller, B.M. Weckhuysen, Chem. Phys. Lett. 397 (2004) 277.

[2] U. Gro Nielsen, N.-Y. Topsoe, M. Brorson, J. Skibsted, H.J. Jakobsen, J. Am. Chem. Soc. 126 (2004) 4926.

[3] S. Szakacs, G.J. Altena, T. Fransen, J.G. Van Ommen, J.R.H. Ross, Catal. Today 16 (1993) 237.

[4] N.-Y. Topsoe, H. Topsoe, Catal. Today 9 (1991) 77.

[5] M. Turco, L. Lisi, R. Pirone, P. Ciambelli, Appl. Catal. B: Environ. 3 (1994) 133.

[6] B.M. Weckhuysen, D.E. Keller, Catal. Today 78 (2003) 25.

[7] I.E. Wachs, Y. Chen, J.-M. Jehng, L.E. Briand, T. Tanaka, Catal. Today 78 (2003) 13.

[8] M.A. Vuurman, I.E. Wachs, J. Mol. Catal. 77 (1992) 29.

[9] B. Olthof, A. Khodakov, A.T. Bell, E. Iglesia, J. Phys. Chem. B 104 (2000) 1516.

[10] N. Das, H. Eckert, H. Hu, I.E. Wachs, J.F. Walzer, F.J. Feher, J. Phys. Chem. 97 (1993) 8240.

[11] L. Jhansi Lakshmi, Z. Ju, E.C. Alyea, Langmuir 15 (1999) 3521.

[12] O.B. Lapina, D.F. Khabibulin, A.A. Shubin, V.M. Bondareva, J. Mol. Catal. A: Chemical $162(2000) 381$.

[13] G. Deo, A.M. Turek, I.E. Wachs, T. Machej, J. Haber, N. Das, H. Eckert, A.M. Hirt, Appl. Catal. A: Gen. 91 (1992) 27.

[14] T. Tanaka, H. Yanmashita, R. Tsuchitani, T. Funabiki, S. Yoshida, J. Chem. Soc., Faraday Trans. 84 (1988) 2987.

[15] J. Haber, P. Nowak, E.M. Serwicka, I.E. Wachs, Bull. Pol. Acad. Sci. 48 (2000) 337.

[16] M.E. Harlin, V.M. Niemi, A.O.I. Krause, B.M. Weckhuysen, J. Catal. 203 (2001) 242.

[17] L.J. Burcham, G. Deo, X. Gao, I.E. Wachs, Top. Catal. 11/12 (2000) 85.

[18] A. Brückner, P. Rybarczyk, H. Kosslick, G.-U. Wolf, M. Baerns, Stud. Surf. Sci. Catal. 142 (2002) 1141.

[19] M. Ruitenbeek, A.J. van Dillen, F.M.F. de Groot, I.E. Wachs, J.W. Geus, D.C. Koningsberger, Top. Catal. 10 (2000) 241.

[20] G.C. Bond, S. Flamerz-Tahir, Appl. Catal. 71 (1991) 1.

[21] G. Deo, I.E. Wachs, J. Haber, Crit. Rev. Surf. Chem. 4 (1994) 141.

[22] I.E. Wachs, B.M. Weckhuysen, Appl. Catal. A: Gen. 157 (1997) 67.

[23] I.E. Wachs, Catal. Today 27 (1996) 437.

[24] S. Takenaka, T. Tanaka, T. Yamazaki, T. Funabiki, S. Yoshida, J. Phys. Chem. B 101 (1997) 9035.

[25] S.T. Oyama, G.T. Went, K.B. Lewis, A.T. Bell, G.A. Somorjai, J. Phys. Chem. 93 (1989) 6786.

[26] H. Eckert, I.E. Wachs, J. Phys. Chem. 93 (1989) 6796.

[27] L.R. Le Coustumer, B. Taouk, M. Le Meur, E. Payen, M. Guelton, J. Grimblot, J. Phys. Chem. 92 (1988) 1230.

[28] X. Gao, S.R. Bare, B.M. Weckhuysen, I.E. Wachs, J. Phys. Chem. B 102 (1998) 10842.

[29] B.M. Weckhuysen, J.-M. Jehng, I.E. Wachs, J. Phys. Chem. B 104 (2000) 7382 .

[30] N. Magg, B. Immaraporn, J.B. Giorgi, T. Schroeder, M. Baumer, J. Dobler, Z. Wu, E. Kondratenko, M. Cherian, M. Baerns, P.C. Stair, J. Sauer, H.-J. Freund, J. Catal. 226 (2004) 88.

[31] D.E. Keller, F.M.F. de Groot, D.C. Koningsberger, B.M. Weckhuysen, J. Phys. Chem. B 109 (2005) 10223. 
[32] B.M. Weckhuysen, L.M. de Ridder, R.A. Schoonheydt, J. Phys. Chem. 97 (1993) 4756.

[33] A. Khodakov, B. Olthof, A.T. Bell, E. Iglesia, J. Catal. 181 (1999) 205.

[34] B.M. Weckhuysen, R.A. Schoonheydt, Catal. Today 49 (1999) 441.

[35] M.F. Guest, I.J. Bush, H.J.J. van Dam, P. Sherwood, J.M.H. Thomas, J.H. van Lenthe, R.W.A. Havenith, J. Kendrick, Mol. Phys. 103 (2005) 719.

[36] R.H. Hertwig, W. Koch, Chem. Phys. Lett. 268 (1997).

[37] P.J. Stephens, F.J. Devlin, C.F. Chabalowski, M.J. Frisch, J. Phys. Chem. 98 (1994).

[38] O. Dmitrenko, W. Huang, T.E. Polonova, L.C. Francesconi, J.A. Wingrave, A.V. Teplyakov, J. Phys. Chem. B 107 (2003) 7747.

[39] A.P. Scott, L. Radom, J. Chem. Phys. 100 (1996) 16502.
[40] M.W. Wong, Chem. Phys. Lett. 256 (1996) 391.

[41] R. Ahlrichs, P.R. Taylor, J. Chim. Phys. 78 (1981) 315.

[42] T.R. Gilson, O.F. Bizri, N. Cheetham, J. Chem. Soc., Dalton Trans. (1973) 291.

[43] L.D. Nguyen, S. Loridant, H. Launay, A. Pigamo, J.L. Dubois, J.M.M. Milet, J. Catal. 237 (2006) 38.

[44] E.W. Deguns, Z. Taha, G.D. Meitzner, S.L. Scott, J. Phys. Chem. B 109 (2005) 5005.

[45] G.L. Rice, S.L. Scott, J. Mol. Catal. A: Chem. 125 (1997) 73.

[46] G.L. Rice, S.L. Scott, Langmuir 13 (1997) 1545.

[47] L.T. Zhuravlev, Colloids Surf. A: Physicochem. Eng. Aspects 173 (2000) 1. 